\title{
Poly(ethylene imine)-Controlled Calcium Phosphate Mineralization
}

\author{
Andriy Shkilnyy, ${ }^{\dagger},{ }^{\dagger}$ Alwin Friedrich,${ }^{\dagger}$ Brigitte Tiersch,${ }^{\dagger}$ Stefanie Schöne, ${ }^{\dagger}$ Mabya Fechner, ${ }^{\dagger}$ \\ Joachim Koetz, ${ }^{\dagger}$ Carl-Wilhelm Schläpfer,$\stackrel{ }{\S}$ and Andreas Taubert $*, \dagger, \ddagger$ \\ Institute of Chemistry, University of Potsdam, D-14476 Golm, Germany, Max-Planck-Institute of Colloids \\ and Interfaces, D-14476, Golm, Germany, and Department of Chemistry, University of Fribourg, CH-1700 \\ Fribourg, Switzerland
}

\begin{abstract}
The current paper shows that poly(ethylene imine) (PEI) is an efficient template for the fabrication of spherical calcium phosphate $(\mathrm{CaP}) /$ polymer hybrid particles at $\mathrm{pH}$ values above 8 . The polymer forms spherical entities, which contain one or a few CaP particles with diameters of ca. $6 \mathrm{~nm}$. The samples contain up to $20 \mathrm{wt} \%$ polymer, which appears to be wrapped around the small $\mathrm{CaP}$ particles. The particles form via a mineralization-trapping pathway, where at the beginning of the precipitation small $\mathrm{CaP}$ particles form. Further particle growth is then prevented by precipitation of the PEI onto these particles at $\mathrm{pH}$ values of ca. 8. Stabilization of the particles is provided by the re-protonation of the PEI, which is adsorbed on the CaP particles, during the remainder of the mineralization process. At low $\mathrm{pH}$, much larger particles form. They most likely grow via heterogeneous nucleation and growth on existing, polymermodified $\mathrm{CaP}$ surfaces.
\end{abstract}

\section{Introduction}

Calcium phosphate $(\mathrm{CaP})$, especially the $\mathrm{CaP}$ crystal phases hydroxyapatite $\mathrm{Ca}_{10}\left(\mathrm{PO}_{4}\right)_{5}(\mathrm{OH})_{2}(\mathrm{HAP})$, octacalcium phosphate $\mathrm{Ca}_{8} \mathrm{H}_{2}\left(\mathrm{PO}_{4}\right)_{6} \cdot 5 \mathrm{H}_{2} \mathrm{O}(\mathrm{OCP})$, brushite $\mathrm{CaHPO}_{4} \cdot 2 \mathrm{H}_{2} \mathrm{O}$ (dicalcium phosphate dihydrate, DCPD), $\beta$-tricalcium phosphate $\mathrm{Ca}_{3}\left(\mathrm{PO}_{4}\right)_{2}$ $\left(\beta\right.$-TCP), and monetite $\mathrm{CaHPO}_{4}$ (dicalcium phosphate anhydrous, DCPA), have in the recent past been widely studied for their potential as bone substitutes or nonviral vectors for gene delivery. ${ }^{1-4}$ Bioinspired and biomimetic mineralization of $\mathrm{CaP}$, that is, the precipitation of $\mathrm{CaP}$ from aqueous solution in the presence of organic or polymeric growth modifiers, has become one of the major tools to fabricate well-defined CaP/organic hybrids.$^{5-8}$ In particular, homopolymers and double-hydrophilic block copolymers are efficient growth modifiers for calcium phosphate. ${ }^{8}$ Depending on the chemistry, molecular weight, $\mathrm{pH}$, and polymer concentration, a wide variety of $\mathrm{CaP}$ crystal phases, crystal shapes, and particle sizes can be generated..$^{5,8-22}$

* Corresponding author: Institute of Chemistry, University of Potsdam, Karl-Liebknecht-Str. 24-25, Building 26, D-14476 Golm, Germany, Tel.: ++49 (0)331977 5773, E-mail: ataubert@uni-potsdam.de.

University of Potsdam.

Max-Planck-Institute of Colloids and Interfaces.

$\S$ University of Fribourg.

(1) Bohner, M. Injury 2000, 31, 37.

(2) Bohner, M.; Gbureck, U.; Barralet, J. E. Biomaterials 2005, 26, 6423.

(3) Kakizawa, Y.; Kataoka, K. Langmuir 2002, 18, 4539.

(4) Kakizawa, Y.; Miyata, K.; Furukawa, S.; Kataoka, K. Adv. Mater. 2004, 16, 699 .

(5) Amjad, Z. Langmuir 1989, 5, 1222.

(6) Colfen, H.; Mann, S. Angew. Chem., Int. Ed. Engl. 2003, 42, 2350.

(7) Mann, S. Biomineralization: Principles and concepts in bioinorganic materials chemistry; Oxford Chemistry Masters Series; Oxford University Press: Oxford, New York, 2001; Vol. 5.

(8) Schweizer, S.; Taubert, A. Macromol. Biosci. 2007, 7, 1085.

(9) Christoffersen, M. R.; Christoffersen, J. J. Cryst. Growth 1988, 87, 51

(10) Tsortos, A.; Nancollas, G. H. J. Colloid Interface Sci. 2002, 250, 159

(11) Nancollas, G. H. Biological Mineralization and Demineralization; Springer: Berlin, 1982.

(12) Tang, R.; Darragh, M.; Orme, C. A.; Guan, X.; Hoyer, J. R.; Nancollas, G. H. Angew. Chem., Int. Ed. 2005, 44, 3698.

(13) Tang, R.; Wang, L.; Orme, C. A.; Bonstein, T.; Bush, P. J.; Nancollas, G. H. Angew. Chem., Int. Ed. 2004, 43, 2697.

(14) Burke, E. M.; Guo, Y.; Colon, L.; Rhima, M.; Veis, A.; Nancollas, G. H. Colloids Surf., B 2000, 17, 49.

(15) De Rooij, J. F.; Heughebaert, J. C.; Nancollas, G. H. J. Colloid Interface Sci. 1984, 100, 350 .
There have been numerous studies on the effect of polyanions on $\mathrm{CaP}$ mineralization, but only a few studies on the influence of polycations. ${ }^{23-26}$ Crowther et al. have investigated the ability of the low molecular weight PEI analogues spermine, spermidine, and putrescine on HAP nucleation and crystallization inhibition. ${ }^{23}$ There, the inhibiting ability was correlated with the charge of the oligo(imines). Putrescine (containing two nitrogens that can be protonated) was the weakest inhibitor and spermine (four nitrogens) the strongest. Unfortunately, no information about the particle morphology and sizes of the precipitates was provided.

In a more recent study, Michel et al. showed that the presence of spermidine is necessary to grow $\mathrm{CaP}$ in liposomes. ${ }^{26} \mathrm{Without}$ spermidine, no precipitation occurs. This shows that polycations should, aside from the more classically studied polyanions, also be investigated in more detail for their role in $\mathrm{CaP}$ nucleation and growth.

Despite these findings, there have been no studies on the PEIcontrolled mineralization of $\mathrm{CaP}$ in bulk solution. To some extent, this is due to the toxicity of linear (LPEI) and branched PEI (BPEI) with high molecular weights. For example, PEI with a molecular weight of $25000 \mathrm{~g} / \mathrm{mol}$ is toxic. However, PEI with a molecular weight of below ca. $2000 \mathrm{~g} / \mathrm{mol}$ and low molecular weight PEI analogues like spermine and spermidine are nontoxic. ${ }^{27-29}$ Moreover, hybrids of PEI and DNA or RNA,

(16) Antonietti, M.; Breulmann, M.; Göltner, C. G.; Cölfen, H.; Wong, K. K. W.; Walsh, D.; Mann, S. Chem.-Eur. J. 1998, 4, 2493.

(17) Peytcheva, A.; Cölfen, H.; Schnablegger, H.; Antonietti, M. Colloid Polym. Sci. 2002, 280, 218.

(18) Rudloff, J.; Antonietti, M.; Cölfen, H.; Pretula, J.; Kaluzynski, K.; Penczek, S. Macromol. Chem. Phys. 2002, 203, 627.

(19) Bigi, A.; Boanini, E.; Bracci, B.; Falini, G.; Rubini, K. J. Inorg. Biochem. 2003, 95, 291

(20) Taubert, A.; Furrer, E.; Meier, W. Chem. Commun. 2004, 2170

(21) Perkin, K. K.; Turner, J. L.; Wooley, K. L.; Mann, S. Nano Lett. 2005 5,1457 .

(22) Amjad, Z. Phosphorus Res. Bull. 2005, 18, 7.

(23) Crowther, R. C.; Pritchard, C. M.; Qiu, S. M.; Soloway, R. D. Liver 1993 13,141 .

(24) Ngankam, P. A.; Lavalle, P.; Voegel, J. C.; Szyk, L.; Decher, G.; Schaaf, P.; Cuisinier, F. J. G. J. Am. Chem. Soc. 2000, 122, 8998.

(25) Ball, V.; Michel, M.; Boulmedais, F.; Hemmerle, J.; Haikel, Y.; Schaaf, P.; Voegel, J. C. Cryst. Growth Des. 2006, 6, 327.

(26) Michel, M.; Arntz, Y.; Fleith, G.; Toquant, J.; Haikel, Y.; Voegel, J.-C.; Schaaf, P.; Ball, V. Langmuir 2006, 22, 2358. 
hybrids of PEI copolymers and DNA or RNA, CaP/DNA hybrids, and $\mathrm{CaP} / \mathrm{DNA} /$ block copolymer hybrids have been suggested as potential vectors for gene therapy. ${ }^{3,4,30-34}$ It is therefore of interest to determine whether PEI or its low molecular weight analogues could be potentially useful for $\mathrm{CaP}$ mineralization control.

This paper shows that PEI leads to spherical $\mathrm{CaP} /$ polymer hybrid particles at high $\mathrm{pH}$. The particle diameter is below 100 $\mathrm{nm}$, and the particles can therefore be viewed as candidates for nonviral gene vectors. The particles are similar to particles reported earlier by Akiyoshi and colleagues ${ }^{35}$ but appear to form via a different mechanism based on precipitation and adsorption of the polymer on preformed particles.

\section{Experimental Section}

1. Materials. Linear Poly(ethylene imine) (LPEI, chemical structure given in the Supporting Information). $50 \mathrm{~g}(0.587 \mathrm{~mol}$ of $\mathrm{N}$ ) of poly(2-ethyl-2-oxazoline) (Aldrich, Mw $50000 \mathrm{~g} / \mathrm{mol}$ ) were refluxed in $700 \mathrm{~mL}$ of $5 \mathrm{M} \mathrm{HCl}$ for 7 days. The white suspension was cooled to room temperature and filtered off. The crude LPEI* $\mathrm{HCl}$ was dissolved in water and precipitated as LPEI by adding $50 \%$ $\mathrm{KOH}$ until the $\mathrm{pH}$ was 11 . The white sticky polymer was filtered off and washed with water to remove residual $\mathrm{KCl}$. The basic LPEI was dissolved in water by adding $\mathrm{HCl}(37 \%)$ until the $\mathrm{pH}$ was 1.5 , precipitated from acetone, filtered, and dried under vacuum at $60{ }^{\circ} \mathrm{C}$ for several days. The yield was $90 \%$. The final product (Mw ca. $22000 \mathrm{~g} / \mathrm{mol}$ ) was analyzed by elemental analysis and ${ }^{1} \mathrm{H}$ NMR. Elemental analysis: calculated $\left(\mathrm{NC}_{2} \mathrm{H}_{6} \mathrm{Cl}\right)_{n}$ : C, 30.2\%; N, 17.6\%; $\mathrm{H}, 7.6 \%$. Experimental C, $29.4 \%$;, $16.5 \%$; H, 10.7\%. The higher $\mathrm{H}$ value in the experimental data is due to some residual water, which cannot be removed by drying. NMR: LPEI*HCl $\left(\mathrm{D}_{2} \mathrm{O}\right.$, TMS): $\mathrm{CH}_{2}$ (br) 3.54 ppm.

Branched Poly(ethylene imine) (BPEI, chemical structure given in the Supporting Information). BPEI (Aldrich, Mw $25000 \mathrm{~g} / \mathrm{mol}$ ) was converted to the hydrochloride BPEI* $\mathrm{HCl}$ by dissolution in water and addition of aqueous $\mathrm{HCl}(37 \%)$ until the $\mathrm{pH}$ was 1.5 . Subsequently, the water was evaporated under vacuum at $60{ }^{\circ} \mathrm{C}$. Elemental analysis: calculated $\left(\mathrm{NC}_{2} \mathrm{H}_{6} \mathrm{Cl}\right)_{n}$ : C, $30.2 \% ; \mathrm{N}, 17.61 \%$; H, 7.60\%. Experimental: C, 28.32\%; N, 15.96\%; H, 7.69\%.

2. Methods. Mineralization. The polyamines were used as hydrochlorides in all experiments. The polyamine concentrations were $4,6,8$, and $10 \mathrm{mg} / \mathrm{mL}$, respectively. In a typical synthesis, 4.5 $\mathrm{mL}$ of a polymer-containing $0.48 \mathrm{M} \mathrm{CaCl}_{2}$ solution were mixed with $4.5 \mathrm{~mL}$ of a polymer-containing $0.24 \mathrm{M}\left(\mathrm{NH}_{4}\right)_{2} \mathrm{HPO}_{4}$ solution. Upon mixing, the solution immediately became milky. Directly after mixing, the $\mathrm{pH}$ was adjusted to $5,7,8$, or 9 using $1 \mathrm{M} \mathrm{KOH}$. Thereafter, the mixtures were gently agitated for 7 days at room temperature. The products were centrifuged at $1500 \mathrm{rpm}$ for $5 \mathrm{~min}$, washed with THF, and dried under vacuum for 2 days.

Potentiometry. Potentiometric titrations were done on a MettlerToledo DL 53 titrator with an Inlab 412 combination electrode at $25^{\circ} \mathrm{C} .40 \mathrm{~mL}$ of a solution of $0.03 \mathrm{M}$ polyamine (LPEI or BPEI) as hydrochloride, $0.01 \mathrm{M}$ hydrochloric acid, and $0.5 \mathrm{M} \mathrm{NaCl}$ were prepared. During titration, $5 \mathrm{~mL}$ of $0.5 \mathrm{M} \mathrm{NaOH}$ was delivered in aliquots of $0.1 \mathrm{~mL}$ from the titrator. The time interval between additions was $90 \mathrm{~s}$. During titration, the temperature was kept at

(27) Thomas, M.; Klibanov, A. M. Proc. Natl. Acad. Sci. U.S.A. 2002, 99, 14640

(28) Thomas, M.; Ge, Q.; Lu, J. J.; Chen, J.; Klibanov, A. M. Pharm. Res. $\mathbf{2 0 0 5}, 22,373$.

(29) Kloeckner, J.; Wagner, E.; Ogris, M. Eur. J. Pharm. Sci. 2006, 29, 414

(30) Welzel, T.; Radtke, I.; Meyer-Zaika, W.; Heumann, R.; Epple, M. J. Mater. Chem. 2004, 14, 2213.

(31) Sirsi, S. R.; Williams, J. H.; Lutz, G. J. Human Gene Ther. 2005, 16, 1307.

(32) Mao, S.; Neu, M.; Germershaus, O.; Merkel, O.; Sitterberg, J.; Bakowsky, U.; Kissel, T. Bioconjugate Chem. 2006, 17, 1209.

(33) Glodde, M.; Sirsi, S. R.; Lutz, G. J. Biomacromolecules 2006, 7, 347.

(34) Sokolova, V.; Radtke, I.; Heumann, R.; Epple, M. Biomaterials 2006, 27, 3147

(35) Sugawara, A.; Yamane, S.; Akiyoshi, K. Macromol. Rapid. Commun. 2006, 27, 441 . $25^{\circ} \mathrm{C}$ by an external thermostat. The titration was carried out under nitrogen. The Inlab 412 combination electrode was calibrated by titrating $45 \mathrm{~mL}$ of a mixture of $0.1 \mathrm{M} \mathrm{NH}_{4} \mathrm{Ac}$ and $0.1 \mathrm{M} \mathrm{HCl}$ before each experiment. The degree of protonation $\left(X_{\mathrm{HP}}\right)$ was calculated via

$$
X_{\mathrm{HP}}=\frac{\mathrm{NH}^{+}}{N_{\text {tot }}}
$$

where $\mathrm{NH}^{+}$is the total amount of protonated nitrogen atoms in moles and $N_{\text {tot }}$ is the total amount of nitrogen atoms in the solution. $\mathrm{NH}^{+}$is calculated after each addition of titrant to the solution by the proton balance

$$
\begin{aligned}
& {\left[\mathrm{NH}^{+}\right]=\frac{C_{\mathrm{HCl}} \times V_{\mathrm{HCl}}+C_{\mathrm{HP}} \times V_{\mathrm{HP}}-C_{\mathrm{NaOH}} \times V_{\mathrm{NaOH}}}{V_{\text {tot }}} } \\
& 10^{-\mathrm{pH}}+\frac{10^{-\mathrm{p} K_{w}}}{10^{-\mathrm{pH}}}
\end{aligned}
$$

$C_{\mathrm{HCl}}$ and $C_{\mathrm{NaOH}}$ are the concentrations, and $V_{\mathrm{HCl}}$ and $V_{\mathrm{NaOH}}$ the volumes of the strong acid and strong base added to the solution of the polymer. The term $C_{\mathrm{HP}} \times V_{\mathrm{HP}}$ gives the number of protons added, if the polymer is used in the protonated form. $C_{\mathrm{HP}}$ is the average concentration of the protonated sites and $V_{\mathrm{HP}}$ the volume of the polymer solution. $V_{\text {tot }}$ is the total volume of the solution and $\mathrm{p} K_{\mathrm{w}}$ is the ion product of water.

Changes of $\mathrm{pH}$ during mineralization were monitored using a Sartorius PP-25 pH meter with a Sartorius PY-P11 pH/ATC combination electrode at $25^{\circ} \mathrm{C}$. Prior to the experiment, the electrode was calibrated using buffer solutions at $\mathrm{pH} 4,7$, and 10 . The initial concentration of the salts and polymers were equal to mineralization experiment described above.

Dynamic Light Scattering and $\zeta$-Potential Measurements. DLS and $\zeta$-potential measurements were carried out on a Malvern Instruments ZEN 3600 device. In a typical experiment, $20 \mathrm{mg}$ of the CaP sample were dispersed in $4 \mathrm{~mL}$ of dust-free water and sonicated for $15 \mathrm{~min}$. The DLS measurement was carried out at a detection angle of $173^{\circ}$.

$X$-ray Diffraction. X-ray diffraction was done on a Nonius PDS 120 with $\mathrm{Cu} \mathrm{K} \alpha$ radiation and position-sensitive detector and on a Nonius D8 with $\mathrm{Cu} \mathrm{K} \alpha$ radiation. Analysis of the XRD patterns was done with OriginLab Origin 6.1.

Electron Microscopy. TEM experiments were made on a Zeiss EM 902 operated at $80 \mathrm{kV}$. Samples were suspended in ethanol, sonicated, and deposited on carbon-coated $\mathrm{Cu}$ grids from the $\mathrm{EtOH}$ suspension. SEM experiments were done on a Hitachi S-4800 operated at $5 \mathrm{kV}$. Prior to SEM imaging, samples were sputtered with Pt/Au using a Balzers SCD 050 Sputter Coater.

Thermal Analysis. TGA and DTA measurements were done in a stationary air atmosphere (no purge) from 30 to $1000{ }^{\circ} \mathrm{C}$ using a Linseis L81 thermal analyzer (Linseis, Germany) working in vertical mode. The heating rate was $10{ }^{\circ} \mathrm{C} / \mathrm{min}$ and $\mathrm{Al}_{2} \mathrm{O}_{3}$ was used as reference. Control experiments were also done at a heating rate of $5{ }^{\circ} \mathrm{C} / \mathrm{min}$ and showed around $5 \%$ deviation from measurements performed at $10^{\circ} \mathrm{C} / \mathrm{min}$.

Infrared Spectroscopy. Transmission IR spectra were recorded on a Thermo Nicolet Nexus 670 Fourier transform infrared (FTIR) spectrometer. Samples were ground with $\mathrm{KBr}$ and pressed into pellets with a hand press. Spectra were recorded at room temperature from 400 to $4000 \mathrm{~cm}^{-1}$ with a resolution of $4 \mathrm{~cm}^{-1}$.

\section{Results and Discussion}

Figure 1 shows powder X-ray diffraction (XRD) patterns of a sample precipitated from solutions at an initial $\mathrm{pH}$ of 5 and an initial $\mathrm{pH}$ of 8 , respectively. XRD reveals that the $\mathrm{pH}$ is the most important parameter for selecting the crystal phase observed after 7 days of mineralization. An initial $\mathrm{pH}$ of 5 always leads to brushite (DCPD) and an initial $\mathrm{pH}$ of 8 always leads to hydroxyapatite (HAP). This finding is independent of the polymer 


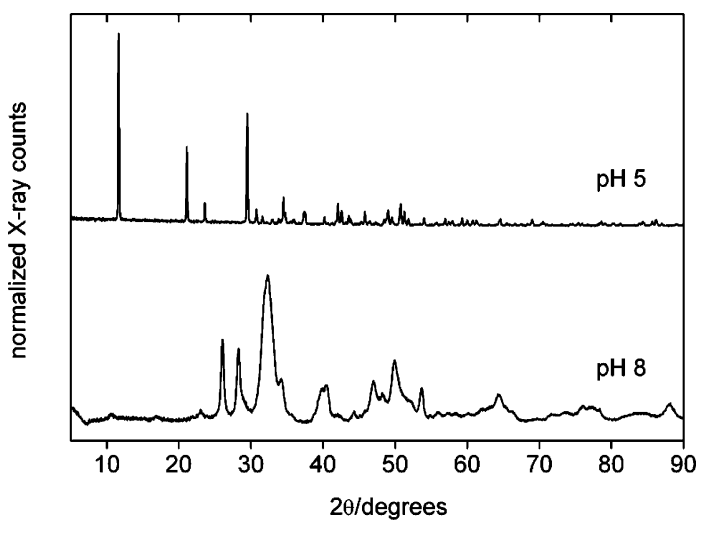

Figure 1. Representative XRD patterns of a calcium phosphate sample obtained from a solution with an initial $\mathrm{pH}$ of 5 (top, LPEI, $10 \mathrm{mg} / \mathrm{mL}$ ) and an initial $\mathrm{pH}$ of 8 (bottom, LPEI, $10 \mathrm{mg} / \mathrm{mL}$ ).

a)

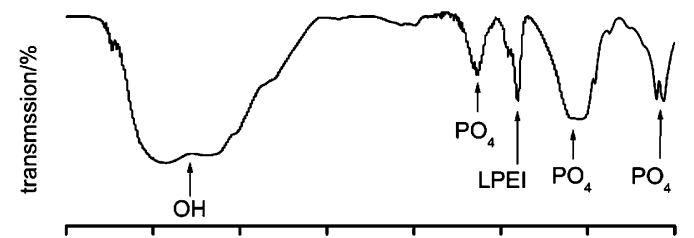

b)

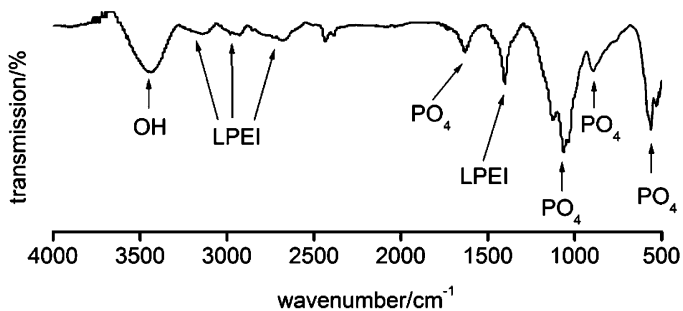

Figure 2. FTIR spectrum of (a) brushite precipitated at $10 \mathrm{mg} / \mathrm{mL}$ of LPEI and an initial $\mathrm{pH}$ of 5 and (b) apatite precipitated at 10 $\mathrm{mg} / \mathrm{mL}$ of LPEI and an initial $\mathrm{pH}$ of 8 .

concentration and the type of polymer (LPEI vs BPEI). Measurements of the $\mathrm{pH}$ after termination of the mineralization also show that some polymer remains in solution or at least in contact with the surrounding bulk solution, as the final $\mathrm{pH}$ increases with increasing polymer concentration. Supporting Information Tables $\mathrm{S} 1$ to $\mathrm{S} 3$ summarize these findings, including a comparison of the peak positions of the samples with published values.

Figure 2 shows representative FTIR spectra of some precipitates. All spectra of brushite exhibit bands indicative of the two water molecules bound per formula unit of brushite and of the - OH vibration of hydrogen phosphate between 3600 and 2500 $\mathrm{cm}^{-1}$. Below $2000 \mathrm{~cm}^{-1}$, there are characteristic bands for the phosphate anion at 550,1065 , and $1620 \mathrm{~cm}^{-1}$ and LPEI vibrations at $1420 \mathrm{~cm}^{-1}$. The spectra of apatite exhibit characteristic bands of $\mathrm{PO}_{4}{ }^{3-}$ at 560,1050 , and $1642 \mathrm{~cm}^{-1}$. The spectra also show broad bands attributed to $\mathrm{OH}^{-}$of hydroxyapatite and adsorbed water at $3450 \mathrm{~cm}^{-1}$, and LPEI vibrations at 3150, 2950 to 2700 , and $1420 \mathrm{~cm}^{-1}$.

Figure 1, Figure 2, and Table S1 (Supporting Information) clearly show that the chemical structure (linear vs branched polymer) does not have an influence on the selection of the polymorph, but the initial $\mathrm{pH}$ of the reaction mixture is the most important parameter to control the polymorph selection. This is not surprising, as the dominating influence of the (initial) $\mathrm{pH}$ on CaP mineralization has been reported several times. ${ }^{9,11,15,36-38}$

(36) Salahi, E.; Moztarzadeh, F. Ceramic Forum International 2001, 78, E43.
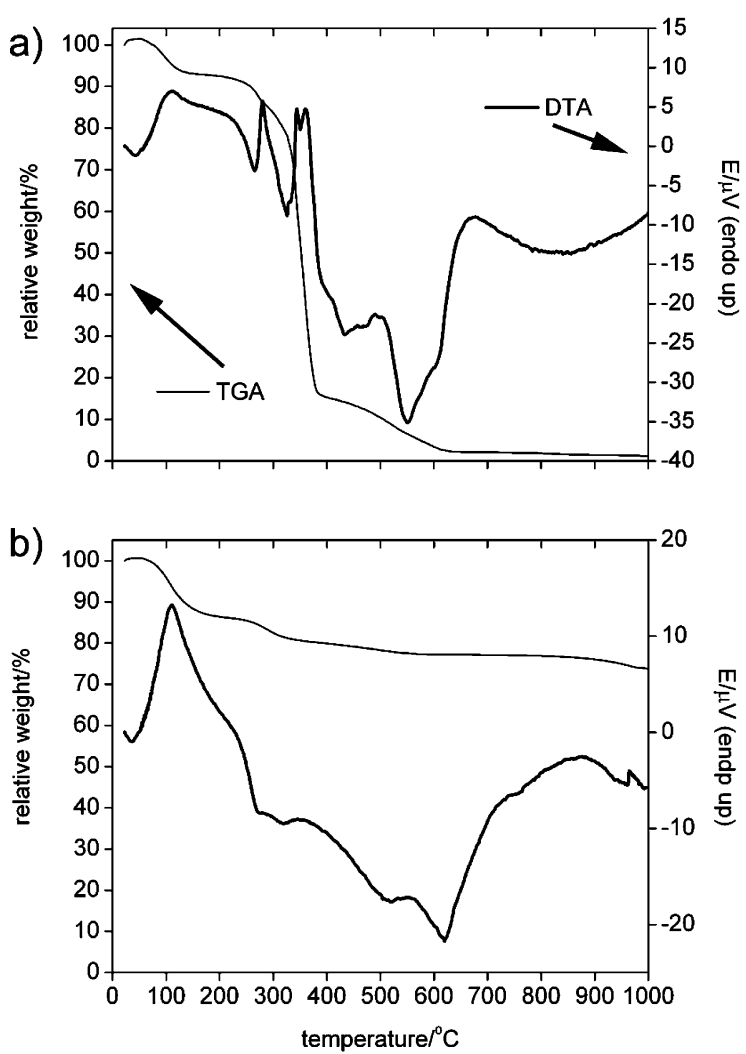

Figure 3. TGA and DTA curves of (a) pure LPEI*HCl and (b) a sample precipitated with $10 \mathrm{mg} / \mathrm{mL}$ of LPEI at an initial $\mathrm{pH}$ of 8 . Note that the scales for the DTA data are not identical.

Figure 3 shows representative thermal analysis data. Thermogravimetric analysis (TGA) and differential thermal analysis (DTA) of the pure LPEI polymer shows that the decomposition of LPEI is a rather complex multistep process. First, an endothermic weight loss is observed at $100{ }^{\circ} \mathrm{C}$, which is immediately followed by another endothermic weight loss at ca. $200{ }^{\circ} \mathrm{C}$. The first weight loss is assigned to removal of water from the sample and the second one to the transformation of the LPEI hydrochloride into LPEI via $\mathrm{HCl}$ removal.

Next, we observe another endothermic weight loss at ca. $280{ }^{\circ} \mathrm{C}$, followed by an exothermic process at $330{ }^{\circ} \mathrm{C}$. These processes are assigned to a first step of polymer decomposition, where the polymer depolymerizes and smaller fragments form. The endothermic signal is presumably caused by an activation process preceding the degradation process, whereas the exothermic process is caused by the depolymerization itself. Finally, another endothermic process at ca. $360{ }^{\circ} \mathrm{C}$ is followed by three to four overlapping broad exothermic processes, which last up to $1000{ }^{\circ} \mathrm{C}$. This process is the thermal decomposition of the polymer and the char that is left at higher temperatures (the "burning"). It takes place until the end of the measurements at $1000{ }^{\circ} \mathrm{C}$. As, even at $1000^{\circ} \mathrm{C}$, the DTA still measures a nonzero $\mu \mathrm{V}$ value, DTA suggests that the decomposition reaction continues up to even higher temperatures, at least under dynamic TGA conditions. In summary, TGA/DTA shows that the thermal decomposition of LPEI is much more complex than previously reported. ${ }^{39}$

(37) Ferraz, M. P.; Monteiro, J.; Manuel, C. M. J. Appl. Biomat. Biomech. 2004, 2, 74.

(38) Honda, Y.; Kamakura, S.; Sasaki, K.; Suzuki, O. J. Biomed. Mater. Res. B 2007, $80 \mathrm{~B}, 281$.

20 
Table 1. Weight Losses of Select Samples between 200 and $500{ }^{\circ} \mathrm{C}$

\begin{tabular}{lccc}
\hline & $\begin{array}{c}\text { polymer } \\
\text { concentration } \\
{[\mathrm{mg} / \mathrm{mL}]}\end{array}$ & initial $\mathrm{pH}$ & $\begin{array}{c}\text { weight loss } \\
\text { polymer }\end{array}$ \\
\hline LPEI & 4 & 5 & 12.0 \\
LPEI & 4 & 8 & 9.0 \\
LPEI & 10 & 5 & 15.0 \\
LPEI & 10 & 8 & 12.4 \\
BPEI & 10 & 5 & 17.9 \\
BPEI & 10 & 8 & 8.0
\end{tabular}

TGA/DTA measurements of the CaP powders show three different processes, which overlap even more strongly than in pure LPEI. At $100^{\circ} \mathrm{C}$, a first endothermic weight loss is assigned to the loss of adsorbed water. Between ca. 300 and $400{ }^{\circ} \mathrm{C}$, TGA/DTA shows an exothermic weight loss, which is again assigned to the depolymerization of the LPEI into smaller fragments. Between 400 and $800{ }^{\circ} \mathrm{C}$, a final exothermic weight loss is assigned to the decomposition (the "burning") of the residual char. Dehydration of the residual calcium phosphate and its transformation into pyrophosphate or oxyapatite will also contribute some to the weight loss; however, this process is endothermic and is therefore probably only a minor contributor to the process. All peaks are broad, and it is therefore difficult to extract contributions from either the final polymer decomposition or the final $\mathrm{CaP}$ dehydration, and only total weight losses for this step can be given.

Table 1 summarizes representative weight losses determined for select samples. All phosphates lose between 10\% and 20\% of their original weight between 200 and $500{ }^{\circ} \mathrm{C}$. TGA does not reveal if the polymer is in or on the precipitates, but provides clear evidence that some material is lost during TGA. Determination of the total organic content (Supporting Information Table S4) also confirms TGA, in that it shows that some organic material (that is, polymer) is associated with the $\mathrm{CaP}$.

However, there is no clear trend with respect to the amount of incorporated polymer (or polymer adsorbed on the surfaces) as a function of initial polymer concentration or initial $\mathrm{pH}$. Although it generally seems that there is more polymer incorporated into samples precipitated at low $\mathrm{pH}$, the stronger hydration of brushite vs HAP has to be taken into account. Overall, the transitions in the TGA/DTA analysis are rather broad and the individual steps often overlap. As a result, it is difficult to determine exactly which contribution to the weight loss is caused by polymer decomposition and by dehydration from either brushite to HAP or from brushite to monetite and then on to HAP. It is possible to conclude, however, that a significant amount of polymer (ca. $10 \mathrm{wt} \%$ ) is incorporated into the precipitate. This is in line with earlier observations where synthetic polyelectrolytes and biopolymers have been incorporated into $\mathrm{ZnO}$ to an extent of over $30 \mathrm{wt} \% .^{40-43}$

Figures 4, 5, and S2 show scanning (SEM) and transmission (TEM) electron micrographs of control samples and samples precipitated in the presence of polymer. Control samples precipitated at $\mathrm{pH} 5$ consist of needle-like crystals with a length of ca. $300 \mathrm{~nm}$. Samples precipitated at pH 8 are also needle-like, but somewhat shorter. Both samples form densely aggregated large blocks consisting of the needle-like crystals.

The presence of the polymeric additive dramatically changes the characteristics of the precipitates. Precipitation at low initial

(40) Taubert, A.; Wegner, G. J. Mater. Chem. 2002, 12, 805

(41) Taubert, A.; Palms, D.; Weiss, Ö.; Piccini, M.-T.; Batchelder, D. N. Chem. Mater. 2002, 14, 2594.

(42) Taubert, A.; Palms, D.; Glasser, G. Langmuir 2002, 18, 4488

(43) Taubert, A.; Kübel, C.; Martin, D. C. J. Phys. Chem B 2003, 107, 2660.
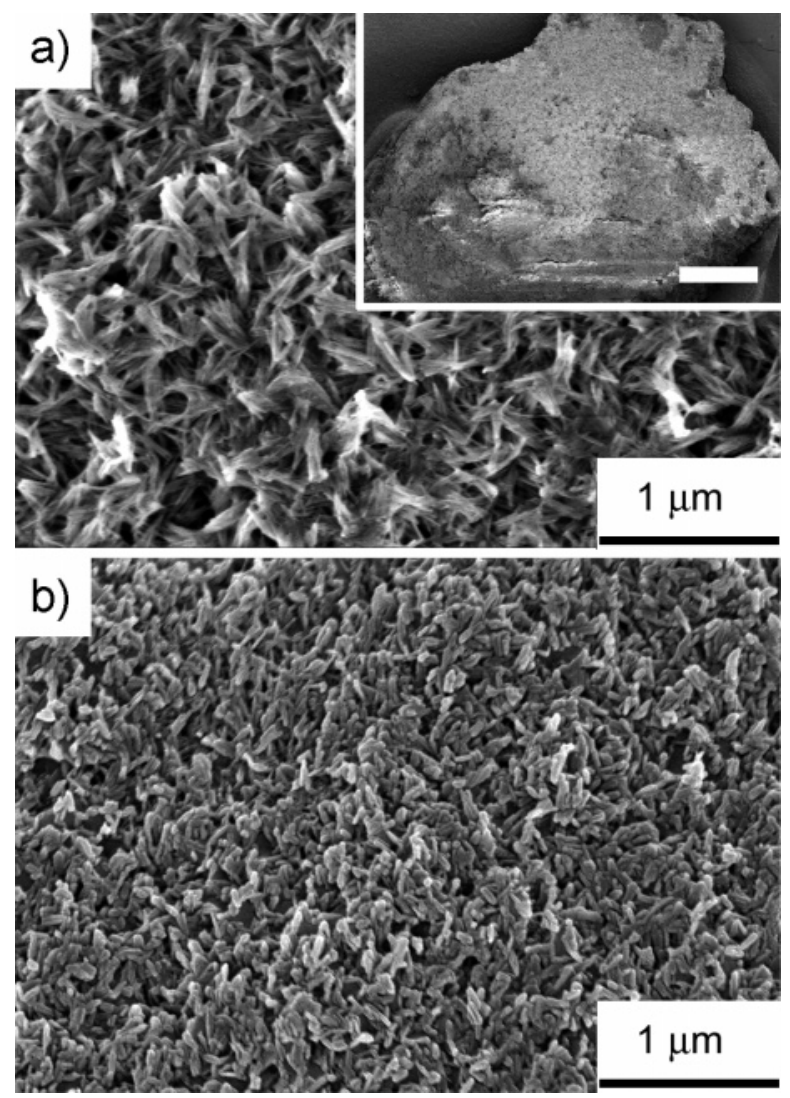

Figure 4. SEM images of control samples precipitated from solutions at starting $\mathrm{pH}$ of (a) 5 and (b) 8, respectively. Inset in (a) shows one of the large blocks mentioned in the text. Scale bar in the inset is $500 \mu \mathrm{m}$.

$\mathrm{pH}$ always yields micrometer-long particles with thick platelet morphology. Occasionally, the platelets also appear to be covered with a fine network or fiber-like structure, but this feature is not always present. The thick plates are rather well ordered, as suggested by TEM. There is also some preliminary evidence for polymer incorporation into the particles from cross-sectional TEM.

High initial $\mathrm{pH}$ values result in sub- $100 \mathrm{~nm}$ spherical particles. This holds for both LPEI and BPEI irrespective of the initial polymer concentration. SEM (Figure S2 in Supporting Information) shows that the particles are highly agglomerated. TEM analysis reveals that they have a uniform spherical shape. Size distribution analysis of the spheres obtained at high initial $\mathrm{pH}$ shows that the particles have an average diameter of 70 to 80 $\mathrm{nm}$. The diameter does not depend on the polymer concentration or polymer type.

A closer inspection of the TEM images reveals that the spherical particles obtained at high initial $\mathrm{pH}$ consist of light gray spheres, which contain smaller dark spheres. We interpret the lighter features of 70 to $80 \mathrm{~nm}$ diameter as polymer spheres, which contain small $\mathrm{CaP}$ particles (the darker features) with a diameter of ca. $6 \mathrm{~nm}$. In this case, TEM suggests that the polymer is wrapped around the $\mathrm{CaP}$ particles rather than incorporated into them.

Mineralization experiments at $\mathrm{pH}$ values above 8 yield the same results; that is, small $\mathrm{CaP}$ particles with a polymer shell form reproducibly at and above $\mathrm{pH}$. The particles observed here are morphologically similar to examples reported by Sugawara et al., ${ }^{35}$ Antonietti et al., ${ }^{44}$ and Roos et al., ${ }^{45}$ where

(44) Antonietti, M.; Grohn, F.; Hartmann, J.; Bronstein, L. M. Angew. Chem. Int. Ed. Engl. 1997, 36, 2080. 

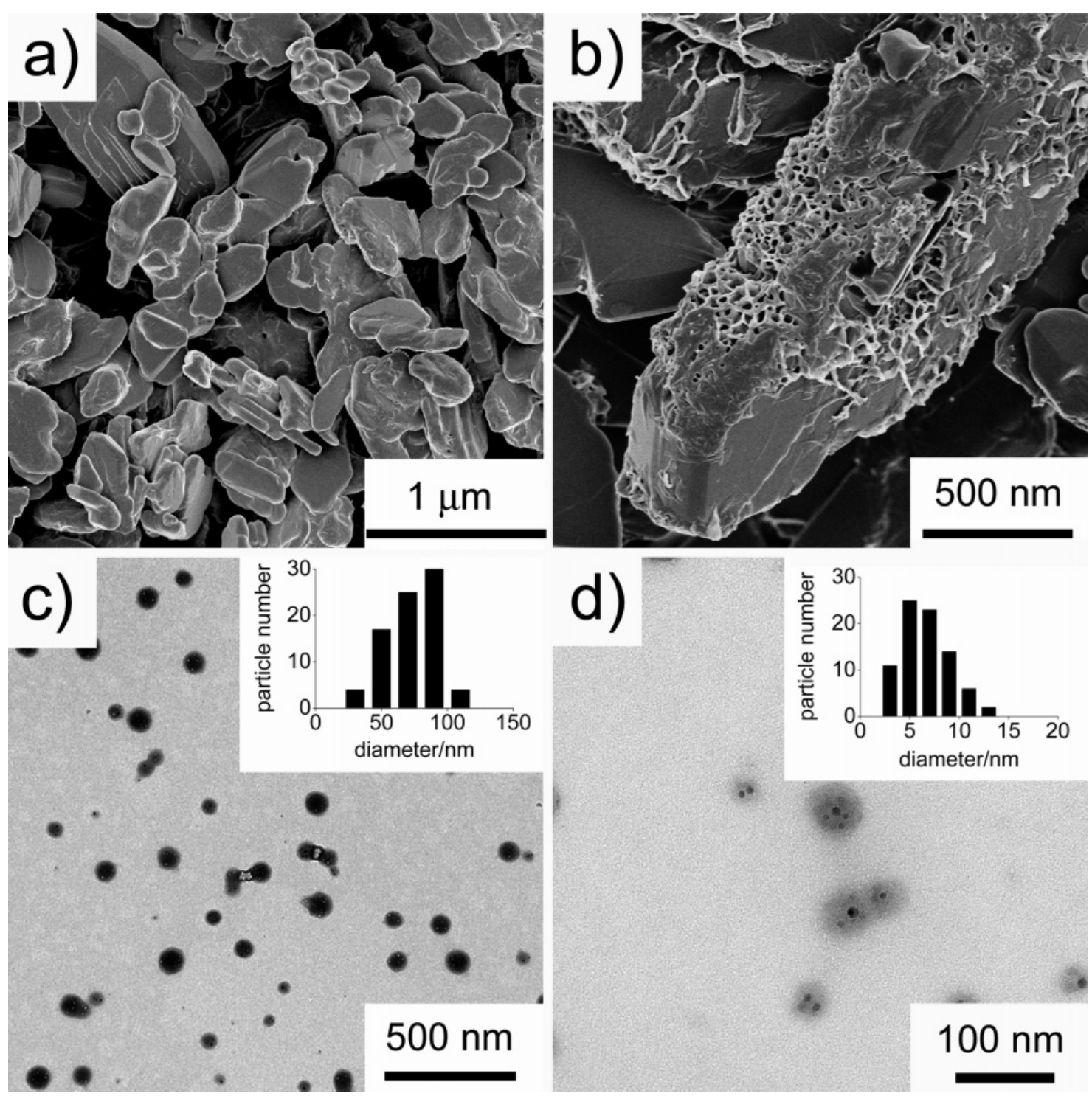

Figure 5. SEM and TEM micrographs of various samples. (a) Sample precipitated with BPEI (4 mg/mL) at pH 5. (b) Sample precipitated with LPEI $(4 \mathrm{mg} / \mathrm{mL})$ at $\mathrm{pH}$ 5. (c) Low-magnification TEM image of a sample precipitated with LPEI $(10 \mathrm{mg} / \mathrm{mL})$ at $\mathrm{pH} 8$. Inset: size distribution histogram of the large particles observed in the micrograph. In this example, the particle diameter is $75 \pm 21 \mathrm{~nm}$. (d) Highmagnification TEM image of the same sample showing the composite nature of the larger spherical particles. Inset: size distribution histogram of the small particles within the larger spheres. In this example, the particle diameter is $6.6 \pm 2.3 \mathrm{~nm}$.

so-called micro- or nanogels were used as templates for the fabrication of polymer/inorganic composite particles.

Figure 6 shows representative dynamic light scattering (DLS) data from a sample prepared at $10 \mathrm{mg} / \mathrm{mL}$ of LPEI and an initial $\mathrm{pH}$ of 8 (small spheres) redispersed in pure deionized water after isolation from the reaction mixture. DLS clearly shows that the polymer/CaP particles shown in Figure 5c,d can be redispersed in water. The particles have a bimodal size distribution with diameters of $225 \pm 56 \mathrm{~nm}$ and $1114 \pm 639 \mathrm{~nm}$, respectively. Number-weighted data clearly show that most particles in the dispersion have a diameter of ca. $225 \mathrm{~nm}$ and that only a few larger agglomerates are present in the solution. Intensity-weighted analysis, however, clearly confirms the presence of some strongly scattering larger aggregates.

The particle radius of the smaller particles is somewhat larger than the diameters of the individual spheres determined from TEM. This is because the polymer shell shrinks to some extent

(45) Roos, C.; Schmidt, M.; Ebenhoch, J.; Baumann, F.; Deubzer, B.; Weis, J. Adv. Mater. 1999, 11, 761. in the TEM because of the high vacuum. In pure water, however, the polymer is highly protonated, which leads to a quite significant swelling. As a result, DLS shows that, in solution, the particles are present as either individual particles, which are highly swollen due to protonation of PEI, or, more likely, as smaller aggregates where only a few particles are aggregated. The rather high charge due to protonation of the LPEI in the redispersed particles is confirmed by $\xi$-potential measurements giving a $\zeta$-potential of $+39.3 \pm 4.7 \mathrm{mV}$ at $25{ }^{\circ} \mathrm{C}$. It is also consistent with earlier findings that $\mathrm{CaP}$ particles precipitated in the presence of polycations have a rather high positive $\zeta$-potential. ${ }^{46,47}$

In summary, SEM, TEM, DLS, IR, and XRD reveal that the polymer architecture (LPEI vs BPEI) and the polymer concentration have no significant influence on the outcome of the mineralization. The initial $\mathrm{pH}$ (5 vs 8 ), in contrast, does play a role: at an initial $\mathrm{pH}$ of 5 , large, thick plates are observed, which

(46) Welzel, T.; Meyer-Zaika, W.; Epple, M. Chem. Commun. 2004, 1204 (47) Urch, H.; Franzka, S.; Dahlhaus, D.; Hartmann, N.; Hasselbrink, E.; Epple, M. J. Mater. Chem. 2006, 16, 1798. 

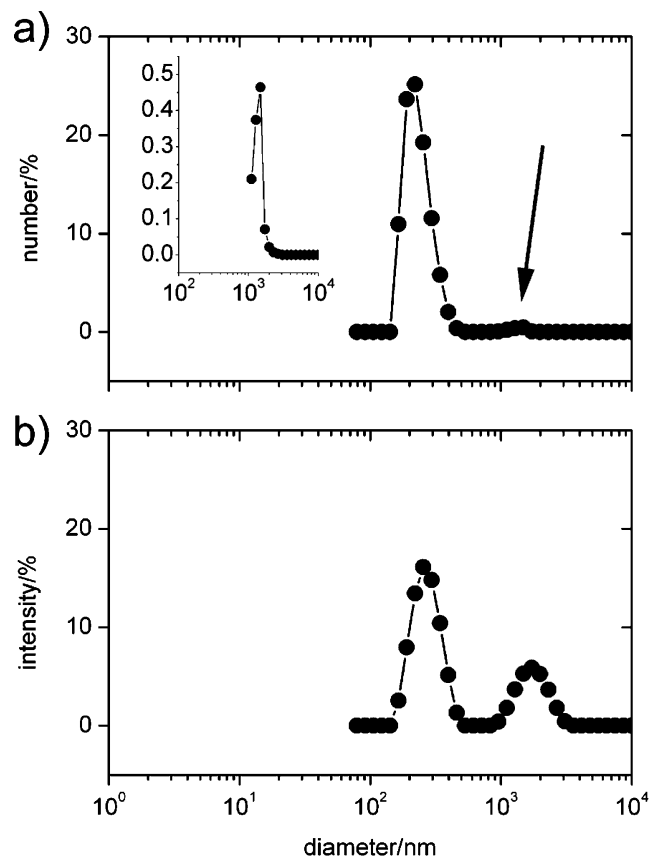

Figure 6. Size distribution of a calcium phosphate sample after dispersion in pure water. The sample was prepared from a solution with $10 \mathrm{mg} / \mathrm{mL}$ of LPEI and an initial $\mathrm{pH}$ of 8 . (a) Number-weighted and (b) intensity-weighted size distribution. Inset in (a) is a magnified view of the peak at ca. $1000 \mathrm{~nm}$ in panel (a) (arrow).

is typical for brushite. At a $\mathrm{pH}$ of 8 and higher, small, spherical composite particles form. There are, however, no variations within one $\mathrm{pH}$ regime, that is, both LPEI and BPEI yield large particles at low initial $\mathrm{pH}$ and small polymer/CaP composite particles at high initial $\mathrm{pH}$. As a result, the polymer concentration or architecture is not the controlling parameter. Moreover, as both LPEI (which partially collapses at pH 8 and forms a physical gel, without precipitating macroscopically) and BPEI (which does not collapse and remains in solution) lead to the same result, the state of the polymer in solution (partially collapsed LPEI vs soluble BPEI) cannot be the primary reason for formation of the observed products.

The main influence must therefore be the degree of protonation of the PEI, that is, the overall charge of the polymers. This is in line with an earlier study on the effect of the low molecular weight PEI analogues spermine, spermidine, and putrescine on HAP nucleation and crystallization inhibition. ${ }^{23}$ There, the inhibiting ability was correlated to the charge of the oligo(imines) and high charges led to strong inhibition. In our case, the templating effect can, to a large extent, also be correlated to the charge of the PEI molecules. Besides the charge, also the $\mathrm{pH}$ of the solution has a strong effect on the relative supersaturation. At $\mathrm{pH}$ values below ca. 4.2, brushite is less soluble, whereas at higher $\mathrm{pH}$ values, apatite is less soluble. ${ }^{48}$

Figure 7 shows the degree of protonation $X_{\mathrm{HP}}$ of LPEI and BPEI as a function of the solution $\mathrm{pH}$. The titration curve of LPEI shows three characteristic features. Up to $\mathrm{pH} 9$, we observe two steps with a less rapid decrease at about $X_{\mathrm{HP}} 0.5$ between $\mathrm{pH} 4.5$ and 6. At $\mathrm{pH} 4.5$, every second amino group is protonated. Therefore, further binding of protons to the amino groups has to take place between two neighboring, already positively charged, sites. As result of the electrostatic repulsion, the local binding constants of this process are lower than in the case of a completely uncharged PEI. This effect is so strong it is not possible to

(48) Calcium Phosphates in Biological and Industrial Systems; Kluwer Academic Publishers: Norwell-Dordrecht, 1998.

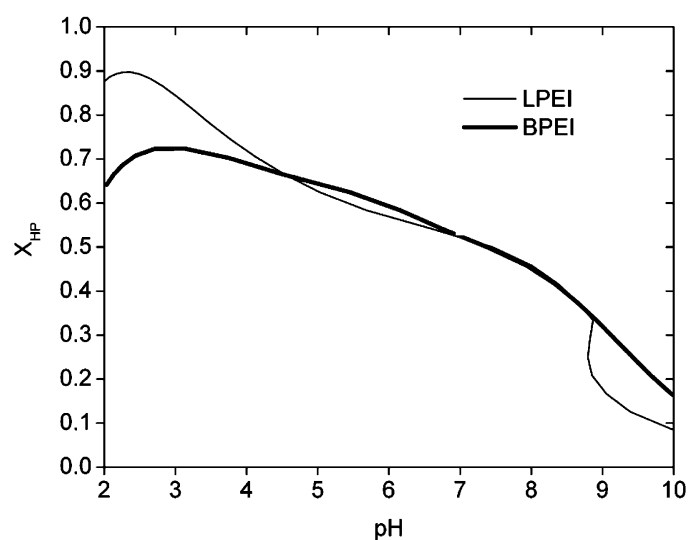

Figure 7. Degree of protonation of the polyamines as a function of $\mathrm{pH}$ at $25^{\circ} \mathrm{C}$.

completely protonate LPEI at $\mathrm{pH} 2$. The maximum $X_{\mathrm{HP}}$ is 0.8 to 0.9 . At pH 5 and $\mathrm{pH} 8$ (where the mineralization experiments were done), the degree of protonation of the polyamines is ca. 0.65 and 0.40 , respectively.

The conformation of LPEI strongly depends on the solution $\mathrm{pH} .{ }^{49}$ With increasing $\mathrm{pH}$, the charge repulsion diminishes and the polymer chain coils, and at $\mathrm{pH}$ values larger than 9 , it becomes insoluble. Upon precipitation, an increase of the $\mathrm{pH}$ and a rapid decrease of $X_{\mathrm{HP}}$ are observed. At a degree of protonation of ca. 0.3 , the electrostatic energy barrier, which inhibits the formation of aggregates in solution, becomes smaller than the thermal energy. The LPEI chains collapse and the excess of protons, which hinder the aggregation, are forced out into solution.

The titration curve of BPEI shows two main differences compared to LPEI. The most important is the absence of the polymer precipitation at high $\mathrm{pH}$. We explain this with the fact that spherical BPEI macromolecules do not readily form a precipitate. Furthermore, the degree of protonation in acidic solution is smaller than for LPEI (only ca. 0.7), indicating a larger electrostatic interaction between the protonated sites. This is because the electrostatic repulsion in BPEI happens in three dimensions as compared to LPEI, where the repulsion is only in one dimension (along the polymer chain).

Figure 8 shows the $\mathrm{pH}$ change over the course of the mineralization process. Solutions at an initial $\mathrm{pH}$ of 5 only exhibit a minor $\mathrm{pH}$ change during precipitation, although there are slight differences. The control sample exhibits a slight $\mathrm{pH}$ increase at the beginning of the precipitation, where the $\mathrm{pH}$ rises from 5.25 \pm 0.10 to $5.42 \pm 0.10$. After ca. $80 \mathrm{~h}$, the $\mathrm{pH}$ is back at $\mathrm{pH} 5.25$. The sample with $4 \mathrm{mg} / \mathrm{mL}$ of LPEI exhibits a constant $\mathrm{pH}$ of 5.20 during the whole reaction, and the reaction solutions with higher LPEI concentrations all have a $\mathrm{pH}$ of $5.00 \pm 0.02$ over the course of the whole reaction. The slightly higher $\mathrm{pH}$ values of the control samples and the sample with only $4 \mathrm{mg} / \mathrm{mL}$ of LPEI are due to the hydrolysis of $\left(\mathrm{NH}_{4}\right)_{2} \mathrm{HPO}_{4}$, which releases ammonia, which in turn increases the $\mathrm{pH}$. At high polymer concentrations, the $\mathrm{pH}$ is lower because of the higher concentration of the LPEI hydrochloride.

If the initial solution $\mathrm{pH}$ is 8 , the $\mathrm{pH}$ is not stable, but drops to 4.60 to 5.00 until the end of the mineralization. There is a first, rather rapid, drop to $\mathrm{pH}$ values between 5.60 and 6.00. This drop is followed by a much slower drop to $\mathrm{pH} 4.60 \pm 0.02$ to 5.00 \pm 0.02 . The first drop is fastest in the control sample and slower with increasing LPEI concentration. Furthermore, the final $\mathrm{pH}$

(49) Kobayashi, S.; Hiroishi, K.; Takunoh, M.; Saegusa, T. Macromolecules 1987, 20, 1496. 

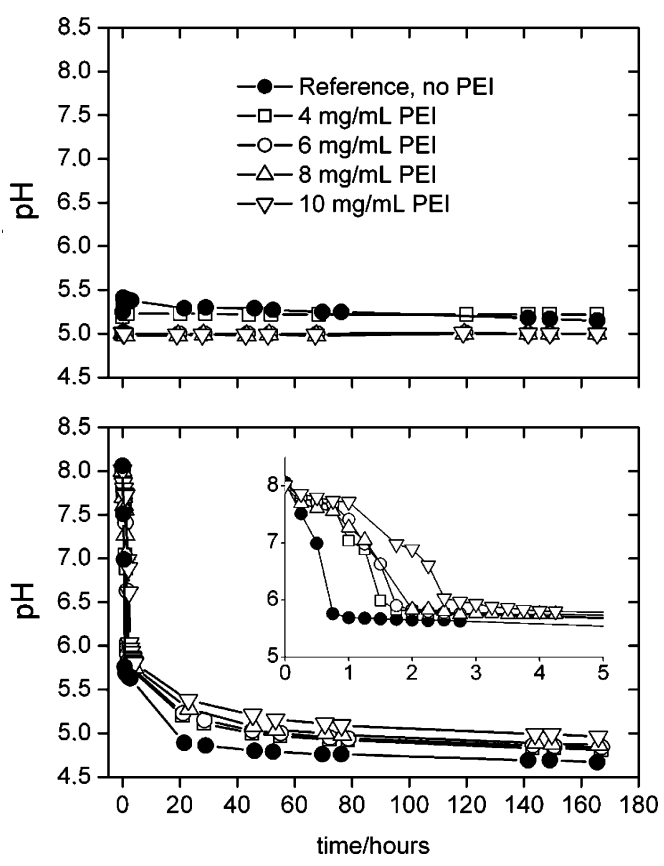

Figure 8. $\mathrm{pH}$ change during mineralization with LPEI. (a) Initial $\mathrm{pH}$ of 5 and (b) initial $\mathrm{pH}$ of 8. Inset: magnified view of first $5 \mathrm{~h}$ when starting from $\mathrm{pH} 8$.

after the precipitation is terminated is also controlled by the LPEI concentration. The lowest $\mathrm{pH}$ is found for the control sample, and the highest value is found for the sample with $10 \mathrm{mg} / \mathrm{mL}$ of LPEI. This is significantly different from the solutions at a starting $\mathrm{pH}$ of 5, where all samples with LPEI concentrations higher than $5 \mathrm{mg} / \mathrm{mL}$ result in the same final $\mathrm{pH}$ value.

This behavior can be rationalized with a simplistic model. At an initial $\mathrm{pH}$ of 5 , the solution contains free protons and there is no release of protons from the $\mathrm{CaP}$ precursors during the mineralization. The $\mathrm{pH}$ increase in the control sample early in the precipitation process is due the hydrolysis of ammonium phosphate. The slightly higher $\mathrm{pH}$ of the solution with only 4 $\mathrm{mg} / \mathrm{mL}$ is due to hydrolysis as well. The solutions with only 4 $\mathrm{mg} / \mathrm{mL}$ of LPEI* $\mathrm{HCl}$ are unable to completely buffer the entire system. At higher LPEI concentrations, the buffer capacity is higher, the protons formed via ammonium phosphate hydrolysis are more efficiently captured, and there is thus no change in the $\mathrm{pH}$. Furthermore, there is no proton release from the $\mathrm{CaP}$ during the mineralization reaction. As a result, the $\mathrm{pH}$ remains quite stable over the course of the whole reaction.

Unlike the formation of brushite at $\mathrm{pH} 5$, the formation of apatite from solutions at an initial $\mathrm{pH}$ of 8 is accompanied by expulsion of protons (from the hydrogen phosphate ion) into the surrounding solution. As a consequence, the $\mathrm{pH}$ decreases during mineralization. The increasing lag time with increasing polymer concentration is probably because LPEI acts as a buffer with a limited capacity; that is, once the PEI is protonated to the highest degree possible under the given conditions, any proton released further during mineralization will decrease the $\mathrm{pH}$. An alternative interpretation is that the PEI delays the precipitation, which would also result in a lag time and a delayed $\mathrm{pH}$ decrease. Time-resolved experiments to determine the reason for the delay are underway.

Finally, for both cases, the phosphate equilibria need to taken into account as well. For both $\mathrm{pH}$ conditions, the $\mathrm{PO}_{4}{ }^{3-}$ content is very low in comparison to other charged and protonated phosphate forms. However, the percentage of the triply charged phosphate ions is more important at $\mathrm{pH} 8$ than at $\mathrm{pH}$. As a result, the presence of phosphate at $\mathrm{pH} 8$ will also favor the formation of HAP, as there a larger amount of phosphate is available for direct incorporation into the growing crystals. In contrast, a lower $\mathrm{pH}$ will yield an even lower fraction of phosphate and correspondingly a higher fraction of hydrogen phosphate, which is favorable for the formation of brushite.

Suggested Growth Model. With the degree of protonation and the solubilities of the polymers taken into account, it is possible to derive a simple explanation for the observed results. The particles grown in the presence of PEI at low initial $\mathrm{pH}$, when both LPEI and BPEI are charged to $65 \%$ to $70 \%$, are much larger than the particles of the control samples. This shows that a highly charged, polycationic polymer is an efficient (heterogeneous) nucleation and growth promoter for $\mathrm{CaP}$. This is in line with earlier findings by Ngankam et al., who have shown that polyelectrolyte multilayers with positive or negative surface charges are efficient nucleators for $\mathrm{CaP} .{ }^{24}$ Furthermore, Michel et al. have shown that spermidine, a low molecular weight analogue of PEI, is necessary to grow $\mathrm{CaP}$ within liposomes. ${ }^{26}$

Our data suggest that, as soon as some particles precipitate, their surface is covered by the LPEI or BPEI. Overall, at pH 5 the surface charge of the precipitate covered with the polymer will then be positive, because the polymer extends loops and trains, which carry positive charges, into the solution. Due to electrostatic attraction, the polymer-coated particle surface will be enriched in phosphate, which will in turn lead to another deposition step of CaP/PEI, as both $\mathrm{Ca}^{2+}$ and PEI are attracted again by the then overall negative charge of the particle surface. This hypothesis is supported by Ball et al., who have shown that poly(L-lysine) surfaces are efficient nucleators for HAP. ${ }^{25}$

At $\mathrm{pH} 8$, the degree of protonation of the polyamines is ca. 0.4 and the polymers are in a more collapsed state. They can be viewed as "nanogels" similar to an example by Sugawara et al. who used hydrophobically modified pullulan as template for the fabrication of $\mathrm{CaP} /$ polymer hybrid particles. ${ }^{35} \mathrm{In}$ the current case, however, an alternative formation process is more likely. When the initial calcium and phosphate solutions, which were adjusted to $\mathrm{pH} 8$ prior to mixing, are mixed, the $\mathrm{pH}$ drops and the originally clear solution becomes turbid. After readjustment to $\mathrm{pH} 8$, the $\mathrm{pH}$ decreases to 4.5 to 5 more slowly, as is evidenced by timeresolved $\mathrm{pH}$ measurements. This slower decrease can be explained with a slower release of protons due to a slower crystal growth, to a buffering activity of the PEI, or to a delayed nucleation and growth.

As a result, we propose the following growth mechanism: at the initial mixing step, $\mathrm{CaP}$ nanoparticles precipitate. At this point, the LPEI is in an extended, highly charged conformation. After readjustment of the $\mathrm{pH}$ to 8 , the LPEI collapses again and traps the small $\mathrm{CaP}$ particles formed during the first few minutes. As the mineralization proceeds, the $\mathrm{pH}$ decreases again due to the release of protons into the solution. As a result, the LPEI charge increases and LPEI increasingly becomes water-soluble again. The parts of the polymer that are not incorporated into or adsorbed onto the $\mathrm{CaP}$ particles extend into the solution and stabilize the nanoparticles.

As a result, our study supports an earlier study by Crowther et al. ${ }^{23}$ in that not only low molecular weight PEI analogues like spermine but also LPEI and BPEI are efficient growth modifiers for $\mathrm{CaP}$. The earlier work provides evidence that charge is the main parameter for inhibiting nucleation. Our study shows that the charge is not only important in inhibiting nucleation, but also, once nucleation has occurred, in controlling the nucleation and growth of subsequent steps of mineralization. Moreover, our data also suggest that a collapsed state of the template is partially involved in controlling the $\mathrm{CaP}$ mineralization. 


\section{Conclusion}

This paper shows that $\mathrm{pH}$-responsive polyamines can be used as efficient templates for the formation of $\mathrm{CaP} /$ polyamine hybrid nanoparticles. Due to its high cytotoxicity, ${ }^{27}$ PEI as such is probably not suited for in vivo applications. Nevertheless, our study supports a few earlier studies showing that not only polyanions, but also polycations have a strong influence on $\mathrm{CaP}$ mineralization. ${ }^{23-26}$ In particular, a new publication by Michel et al. $^{26}$ is interesting in this context. It shows that $\mathrm{CaP}$ mineralization can, in special cases, only proceed if a polycation is present in the reaction mixture. As a result, our data in conjunction with the other reports suggest that it is necessary to also consider the effects of cationic growth modifiers for $\mathrm{CaP}$ mineralization. Further studies into this topic are underway.
Acknowledgment. The authors thank I. Zenke for help with XRD measurements and Prof. H.-J. Holdt for access to his IR spectrometer. A.S. acknowledges the MPI of Colloids and Interfaces for a postdoctoral fellowship. We thank the Swiss National Science Foundation, the MPI of Colloids and Interfaces (Colloid Chemistry Department), and the University of Potsdam for financial support. 